\title{
Comparison of the Effects of Growth Hormone and Insulin-like Growth Factor I on Substrate Oxidation and on Insulin Sensitivity in Growth Hormone-deficient Humans
}

\author{
Mehboob A. Hussain, ${ }^{\star}$ Ole Schmitz, ${ }^{\ddagger}$ Annette Mengel, ${ }^{\ddagger}$ Yvonne Glatz, ${ }^{\star}$ Jens. S. Christiansen, ${ }^{\star}$ \\ Jürgen Zapf, * and E. Rudolf Froesch* \\ *Division of Endocrinology and Metabolism, Department of Internal Medicine, University Hospital of Zürich, 8091 Zürich, Switzerland; \\ and ${ }^{\ddagger}$ Department of Medicine II, University Hospital of Aarhus, 8000 Aarhus, Denmark
}

\begin{abstract}
Insulin-like growth factor-I (IGF-I) is considered to be the mediator of the growth-promoting effects of growth hormone (GH). The metabolic effects of these two hormones, however, are different. Whereas GH treatment leads to elevated insulin and glucose levels, reduced insulin sensitivity, and impaired glucose tolerance, IGF-I treatment leads to reduced insulin and GH levels and enhanced insulin sensitivity. IGF-I may, therefore, not only be the mediator of the growth-promoting effects of GH but also a modulator of the effects of GH on insulin action and glucose metabolism. To study the influence of GH and IGF-I on substrate metabolism and insulin sensitivity (assessed by euglycemic, hyperinsulinemic clamping combined with indirect calorimetry and glucose tracer infusion), we have treated eight GHdeficient adults with $\mathrm{GH}\left(2 \mathrm{IU} / \mathrm{m}^{2}\right.$ daily subcutaneously [s.c.]), IGF-I (10 $\mu \mathrm{g} / \mathrm{kg} \cdot \mathrm{h}$ s.c.), or both hormones together for $7 \mathrm{~d}$, respectively, and compared the effects of these treatment regimens with a control phase. Our findings suggest that $(a)$ both GH and IGF-I promote lipolysis and lipid oxidation, albeit by different mechanisms; (b) treatment with either hormone is followed by enhanced energy expenditure and reduced protein oxidation; and (c) IGF-I reverses the insulin resistance induced by GH. (J. Clin. Invest. 1994. 94:1126-1133.) Key words: substrate oxidation • insulin sensitivity • euglycemic clamp • lipolysis • energy expenditure
\end{abstract}

\section{Introduction}

Growth hormone (GH) ${ }^{1}$ and insulin-like growth factor I (IGFI) are anabolic and growth-promoting hormones. IGF-I, which is synthesized mainly in hepatocytes under GH stimulation (1),

Address correspondence to Mehboob Hussain, M.D., Division of Endocrinology and Metabolism, Department of Internal Medicine, University Hospital of Zürich, Rämistr. 100, 8091 Zürich, Switzerland.

Received for publication 23 December 1993 and in revised form 14 April 1994.

1. Abbreviations used in this paper: AUC, area under the curve; Cpeptide, connecting peptide; FFM, fat free mass; GH, growth hormone; HGO, hepatic glucose output; iAUC, incremental AUC; nonox, nonoxidative; ox, oxidative; $R_{\mathrm{d}}$, rate of glucose disposal.

J. Clin. Invest.

(C) The American Society for Clinical Investigation, Inc.

0021-9738/94/09/1126/08 \$2.00

Volume 94, September 1994, 1126-1133 is considered to be the mediator of many of the effects of GH (2). IGF-I stimulates growth in situations where GH is lacking $(3,4)$ and in GH insensitivity (Laron-type) dwarfism (5). Treatment with IGF-I in normal adults is accompanied by elevated energy expenditure and lipid oxidation and reduced protein oxidation (6). These changes are similar to those seen during GH treatment (7). Thus, IGF-I could be considered to be the mediator of both the growth-promoting and the metabolic effects of GH. However, some differences between GH and IGF-I with respect to metabolic and endocrine effects are apparent. GH treatment leads to elevated insulin and glucose levels and relative insulin resistance (7-10). In contrast, IGF-I administration reduces growth hormone, insulin, and glucose levels (11) and enhances insulin sensitivity in humans (6). Enhanced insulin sensitivity may arise either by direct action of IGF-I or as a result of partial inhibition of $\mathrm{GH}$ secretion by way of feedback control $(6,11,12)$. Thus, it remains unclear whether IGF-I would also enhance insulin sensitivity when GH levels remain unchanged. Furthermore, IGF-I directly inhibits insulin secretion from the pancreatic $\beta$-cells (13). The question, therefore, may be asked whether induction of insulin resistance by GH and simultaneous reduction of insulin levels by IGF-I may have synergistic metabolic effects when both hormones act together.

To address these questions, IGF-I and GH were administered separately as well as in combination to eight GH-deficient adults. The effects of these regimens on insulin sensitivity, energy expenditure, and total body fuel metabolism were examined and were compared with a control phase without hormone treatment.

The data show that the effects of IGF-I and GH are synergistic with respect to the stimulation of energy expenditure, lipid oxidation, and the inhibition of protein oxidation, whereas they balance each other with respect to basal and stimulated insulin secretion and glucose metabolism.

\section{Methods}

Subjects and experimental protocol. Eight GH-deficient subjects (age range: $21-62$, body mass index: $24.5 \pm 3.5 \mathrm{~kg} / \mathrm{m}^{2}$; Table I) were studied after obtaining written informed consent. The study protocol had been approved by the ethical committee of the University Hospital of Zürich. In all subjects, the previous hormone replacement therapy was maintained unchanged. Two subjects (patients 5 and 6 ) were treated with bromocriptine for residual hyperprolactinemia after surgery and/or radiotherapy. Mental and physical illness apart from pituitary insufficiency was excluded by history, physical and laboratory tests, and chest $\mathrm{x}$ ray. GH deficiency was diagnosed by an insulin stimulation test $(0.1 \mathrm{mU} /$ $\mathrm{kg}$ intravenously). A rise of GH levels to maximally $5 \mathrm{ng} / \mathrm{ml}$ in response to hypoglycemia was considered as diagnostic. Total IGF-I levels before therapy were below $15 \mathrm{nmol} / \mathrm{liter}(9.5 \pm 4.5 \mathrm{nmol} / \mathrm{liter})$. None of the 
Table I. Patient Characteristics

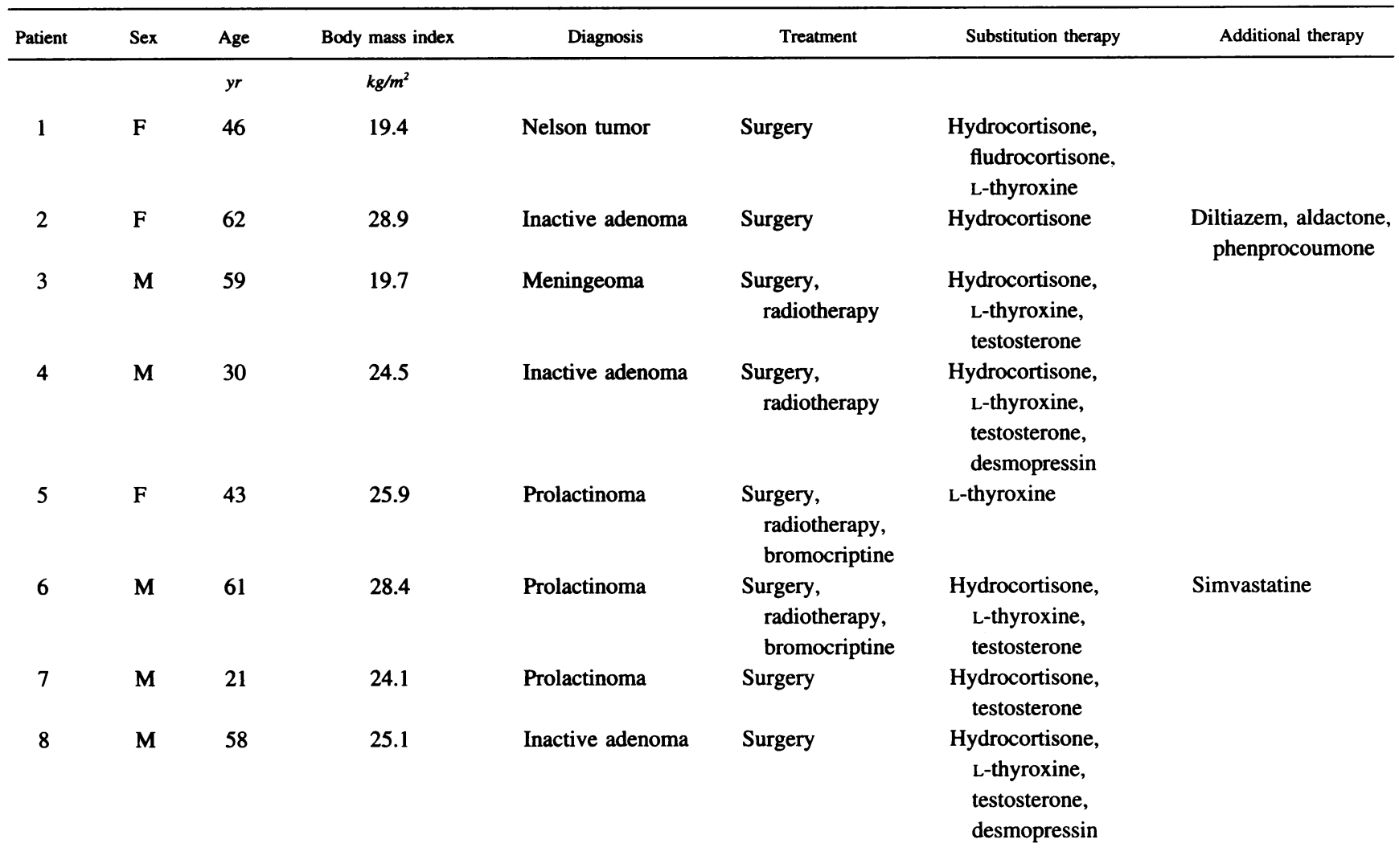

patients had previously received GH substitution therapy. The study protocol consisted of two treatment periods of 2 wk each, arranged in a crossover, randomized fashion. The control period during the first 7 d consisted of no additional treatment apart from the usual hormonal substitution therapy followed by $7 \mathrm{~d}$ of recombinant human IGF-I ( 10 $\mu \mathrm{g} / \mathrm{kg} \cdot \mathrm{h}$ subcutaneously [s.c.]; Ciba-Geigy AG, Basel, Switzerland) treatment which was administered as a continuous subcutaneous infusion with a portable minipump (MRS-1; Disetronic, Burgdorf, Switzerland). Before the other study period, the subjects received $\mathrm{GH}\left(2 \mathrm{IU} / \mathrm{m}^{2}\right.$ s.c. daily at bedtime; Norditropin, Novo-Nordisk, Gentofte, Denmark) for $14 \mathrm{~d}$. This treatment interval was chosen to allow the metabolic changes after GH therapy to develop (8). The subjects were then studied during a further 7-d period of GH treatment, to which IGF-I was added for another $7 \mathrm{~d}$ (at the same respective doses as above). Doses of IGF-I and $\mathrm{GH}$ were so chosen that profound and comparable changes in basal energy expenditure could be expected (references 6 and 8, see Results). All participants were instructed to follow a constant, weight-maintaining diet of $30 \mathrm{kcal} / \mathrm{kg}$ per day ( $30 \%$ for the three main meals and $10 \%$ as bedtime snack; $50 \%$ carbohydrates, $30 \%$ lipids, $20 \%$ proteins) during the whole study. A daily maximum of $\mathbf{3 0}$ min of physical exercise was allowed during the entire study period. Blood samples were drawn after a 10-h overnight fast on days 6 and 7 of each treatment phase for determinations of glucose, insulin, connecting (C)-peptide, total IGFI, total IGF-II, and GH. On days 1, 6, and 7, the subjects stayed at the clinical research center where all meals were served.

Meal tolerance test, euglycemic hyperinsulinemic clamp, and indirect calorimetry. On day 6 , breakfast was substituted by a meal tolerance test in six patients (patients 3-8) as described (14). Briefly, breakfast ( $9 \mathrm{kcal} / \mathrm{kg}$; $50 \%$ carbohydrates, $30 \%$ lipids, $20 \%$ proteins) was served. Blood samples were taken from a cannulated forearm vein at $-30,0$, $30,60,90,120,180$, and 240 min after breakfast for determinations of venous glucose, insulin, and C-peptide (Fig. 1). On day 7, a euglycemic hyperinsulinemic clamp, combined with the isotope dilution technique and indirect calorimetry, was performed according to principles outlined previously (15) with a primed ( $20 \mu \mathrm{Ci})$, continuous $(0.2 \mu \mathrm{Ci})$ infusion of HPLC-purified $3\left[{ }^{3} \mathrm{H}\right]$ glucose (DuPont/New England Nuclear, Boston, MA) starting at $0 \mathrm{~min}$ and an insulin infusion $(0.6 \mathrm{mU} / \mathrm{kg} \cdot \mathrm{min})$ starting at $150 \mathrm{~min}$. Plasma glucose concentration was maintained constant at $5 \mathrm{mmol} / \mathrm{liter}$, using a variable glucose infusion $(200 \mathrm{~g} / \mathrm{liter})$ which contained $200 \mu \mathrm{Ci} 3\left[{ }^{3} \mathrm{H}\right]$ glucose/liter to avoid "negative" rates of hepatic glucose production (16). The last $30 \mathrm{~min}$ during basal conditions (120-150 $\mathrm{min}$ ) and again during insulin stimulation (270-300 $\mathrm{min}$ ) were considered to represent a steady state. Arterialized (6) blood samples for determination of IGF-I, IGF-II, GH, insulin, C-peptide, free fatty acids (FFA), $\beta$-hydroxybutyric acid, and of the specific activity of glucose were collected and treated as described previously (6). Samples were stored at $-20^{\circ} \mathrm{C}$ until assays were performed. Plasma glucose concentration was monitored every 5-10 min. Respiratory gas exchange and energy expenditure were measured by indirect calorimetry using a computerized, flowthrough canopy gas analyzer system (Deltatrac; Datex, Helsinki, Finland). Urine was collected during the euglycemic clamp for calculation of protein oxidation during indirect calorimetry. Fat free mass (FFM) was measured on day 7 using the bioimpedance method (17).

Analytical determinations. All assays were performed according to previously detailed descriptions (6). Plasma glucose was measured immediately after blood sampling using an automated glucose-oxidase method (Glucose Analyzer 2; Beckman Instruments, Inc., Fullerton, CA). Insulin, C-peptide, GH levels, and total IGF-I and IGF-II were measured by double antibody RIA. FFA were determined colorimetrically with a commercial kit (Wako Chemicals, Neuss, Germany). $\beta$ Hydroxybutyric acid was analyzed by a Cobas Bio (Roche Products Ltd., Welwyn Garden City, UK). Tritiated glucose activity was determined after deproteinizing plasma with $0.3 \mathrm{mmol} /$ liter $\mathrm{Ba}(\mathrm{OH})_{2}$ and $0.3 \mathrm{mmol} /$ liter $\mathrm{ZnSO}_{4}$. Subsequently, the supernatant was evaporated under vacuum. The pellet was resuspended in distilled water, supple- 

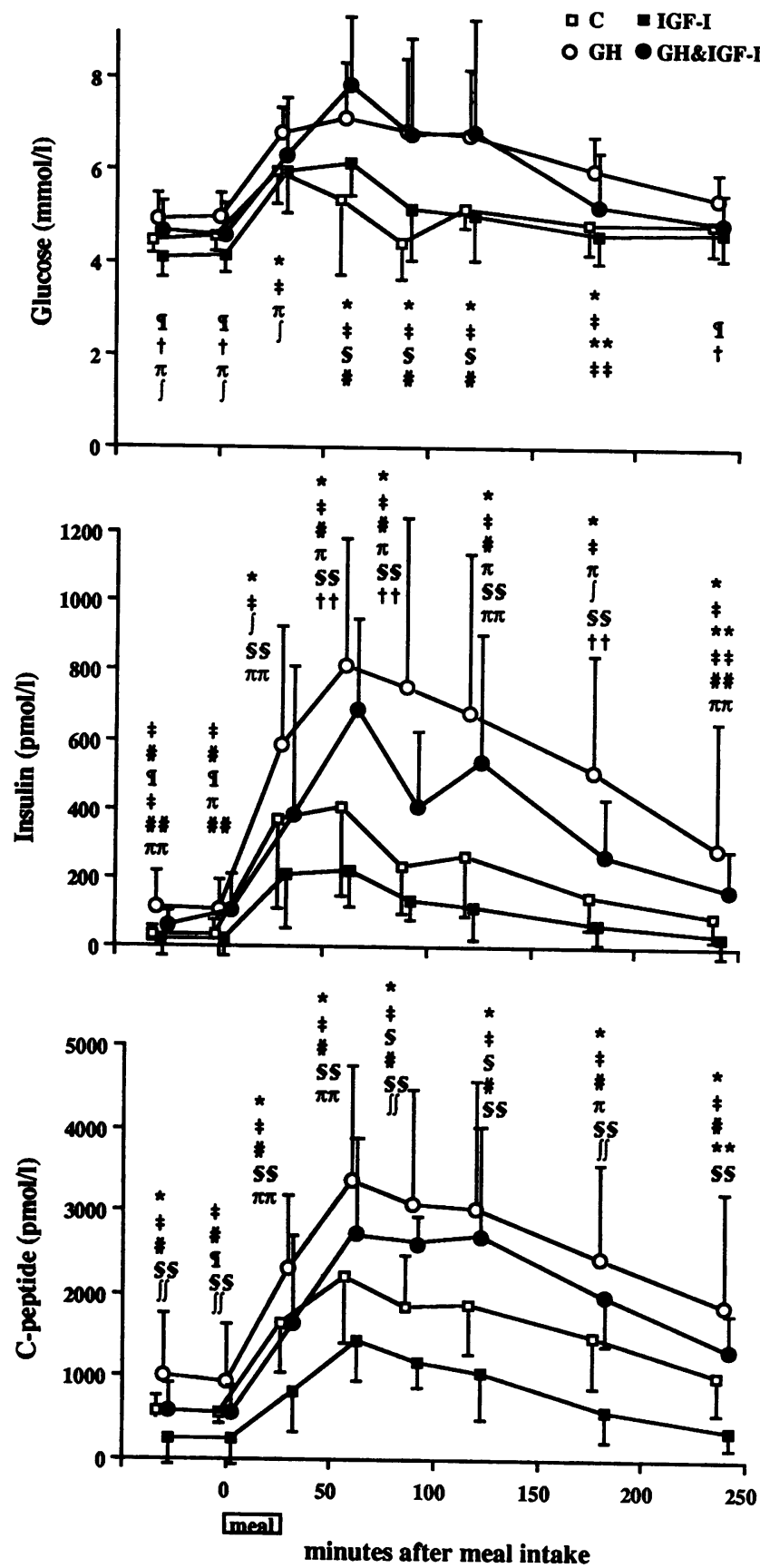

Figure 1. Glucose, insulin, and C-peptide levels during a meal tolerance test in six GH-deficient subjects on day 6 of control $(C)$, IGF-I, GH, and GH\&IGF-I treatment (mean \pm SD, ANOVA, $* P<0.02$ GH vs $C$, ${ }^{\ddagger} P<0.02$ GH vs IGF-I, ${ }^{8} P<0.02$ GH\&IGF-I vs $C,{ }^{*} P<0.02$ GH\& IGF-I vs IGF-I, ${ }^{\top} P<0.03 \mathrm{GH}$ vs $\mathrm{C},{ }^{\dagger} P<0.03 \mathrm{GH}$ vs IGF-I, ${ }^{\pi} P<$ 0.03 GH\&IGF-I vs $C,{ }^{f} P<0.03$ GH\&IGF-I vs IGF-I, $* * P<0.04$ GH\&IGF-I vs $C,{ }^{\ddagger \neq} P<0.04$ GH\&IGF-I vs IGF-I, ${ }^{88} P<0.02$ IGF-I

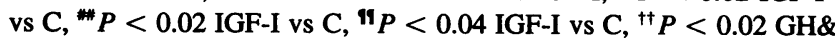
IGF-I vs GH, ${ }^{\pi x} P<0.03$ GH\&IGF-I vs GH, ${ }^{\int S} P<0.04$ GH\&IGF-I vs GH; for AUC see Table V).

mented with $5 \mathrm{ml}$ of Aqualuma Plus (Lumac, Shaesburg, The Netherlands), and counted for $3 \mathrm{~h}$ in a liquid scintillation counter. Urinary urea was measured in an autoanalyzer (Hitachi 747). All samples were analyzed in triplicate (tritiated glucose activity) or duplicate (all other) in one or two dilutions. Care was taken to examine samples from the same individual in the same assay.

Calculations. Areas under the curves were calculated by the trapezoidal rule. Calculation of substrate oxidation rates was performed as outlined previously (18). The gaseous exchange attributable to protein oxidation was subtracted from total gaseous exchange, under the assumption that for each gram of nitrogen excreted in urine 5.95 liters of $\mathrm{O}_{2}$ were consumed, and 4.97 liters of $\mathrm{CO}_{2}$ were produced. The protein oxidation rate was estimated from urinary nitrogen excretion $(1 \mathrm{~g}$ nitrogen $=6.25 \mathrm{~g}$ protein ). Urinary nitrogen excretion was estimated on the assumption that $90 \%$ of the nitrogen appeared as urea. Rates of glucose disposal $\left(\boldsymbol{R}_{\mathrm{d}}\right)$ and glucose appearance were estimated according to the non-steady state equations of Steele as modified by deBodo (19). A pool fraction of 0.65 and a distribution volume of $220 \mathrm{ml} /$ liter for glucose were assumed. Nonoxidative glucose disposal rate $\left(\boldsymbol{R}_{\mathrm{dnonox}}\right)$ was calculated by subtracting the calorimetrically determined oxidative glucose disposal $\left(R_{\mathrm{dox}}\right)$ from the total glucose disposal rate $\left(R_{\mathrm{d}}\right)$. Insulin sensitivity index was calculated as described by Bergman et al. (20) (sensitivity index $=\Delta R_{\mathrm{d}}$ /glucose $\cdot \Delta$ insulin). Separate indices were calculated for $\boldsymbol{R}_{\mathrm{dox}}$ and $\boldsymbol{R}_{\mathrm{dnonox}}$ (Table II). Reasons for calculating insulin sensitivity index were that basal and steady state insulin levels during the clamps varied in the different treatment periods, and to account for any possible insulin-like effects of IGF-I. The latter could be considered constant since the respective IGF-I levels did not change during clamping (see Results and reference 20). Energy expenditure and substrate oxidation rates are given in kilocalories per kilogram of FFM per day (Fig. 2). Basal glucose turnover data are given in milligrams per kilogram of FFM per minute (Table III).

Statistics. All data are expressed as mean \pm SD. Comparisons were performed by ANOVA (21). A $P<0.05$ was considered statistically significant.

\section{Results}

Side effects. Patient 2 reported symptoms of hypoglycemia at 11:00 a.m. of day 4 of IGF-I treatment when she had not taken breakfast. Patient 7 complained of orthostatic vertigo during the IGF-I treatment period only. All patients reported slight parotid tenderness and slight generalized, nonpitting subcutaneous oedema. Patients 4 and 8 reduced their desmopressin dosage, and patient 2 was treated with furosemide $(40 \mathrm{mg} / \mathrm{d})$ because of excessive oedema during the GH + IGF-I protocol. One patient complained of headache and nausea during the combined GH and IGF-I treatment period. Clinical examination and a computer tomography at that time revealed no signs of elevated intracranial pressure. The symptoms regressed over $6 \mathrm{~h}$ after stopping the subcutaneous IGF-I infusion.

Basal parameters. Fasting plasma glucose and serum total IGF-I and IGF-II, GH, insulin, and C-peptide levels in arterialized blood on day 7 are given in Table IV. IGF-I treatment had no detectable effect on pharmacokinetics of exogenous GH. Fasting plasma glucose levels on day 7 were slightly but not significantly reduced during IGF-I treatment as compared with the control period. On day 7 of GH and combined GH + IGFI treatment, basal glucose levels were significantly increased. Basal insulin levels were reduced during IGF-I as compared with control. During GH treatment, fasting insulin levels were significantly elevated and were again reduced during additional IGF-I treatment. Basal C-peptide levels behaved similarly. Basal circulating FFA (Fig. 3) were elevated during treatment with IGF-I $(677 \pm 88)$ and with GH $(764 \pm 272)$ as compared with control (523 \pm 96$)$ and were elevated to even higher levels during the combination therapy (823 $\pm 203 \mu \mathrm{mol} /$ liter). $\beta$-Hydroxybutyric acid levels changed in parallel with the FFA (con- 
Table II. Insulin Sensitivity Index, Hepatic Glucose Output, and Calculated Oxidative and Nonoxidative Rate of Disposal Indices during Euglycemic, Hyperinsulinemic Clamp on Day 7 of Control, IGF-I, GH, and GH + IGF-I Treatment in Eight GH-deficient Subjects

\begin{tabular}{|c|c|c|c|c|}
\hline & Control & IGF-I & GH & GH + IGF-I \\
\hline Insulin sensitivity index $\left(\Delta R_{d} /\right.$ glucose $\cdot \Delta$ insulin $)(\mathrm{mg} / \mathrm{kg}[F F M] \cdot \mathrm{mmol} / \mathrm{iter} \cdot \mathrm{nmol} / \mathrm{iter})$ & $3.2 \pm 2.3$ & $4.5 \pm 2.3^{*}$ & $1.9 \pm 0.7^{* \ddagger}$ & $2.6 \pm 0.7^{8 \mid 19}$ \\
\hline $\mathrm{HGO}(\mathrm{mg} / \mathrm{kg}[F F M] \cdot \min )$ & $-0.1 \pm 0.6$ & $0.3 \pm 0.4$ & $0.9 \pm 0.4^{\S}$ & $1.0 \pm 0.3^{8 \|}$ \\
\hline \multicolumn{5}{|l|}{ Glucose disposal rate index $(\mathrm{mg} / \mathrm{kg}[F F M] \cdot \mathrm{mmolhlter} \cdot \mathrm{nmol} / \mathrm{iter})$} \\
\hline Oxidative $\left(\Delta R_{\text {dox }} /\right.$ glucose $\cdot \Delta$ insulin $)$ & $1.4 \pm 0.4$ & $2.2 \pm 0.6^{*}$ & $1.3 \pm 0.5^{\ddagger}$ & $1.5 \pm 0.6^{\ddagger}$ \\
\hline Nonoxidative $\left(\Delta R_{\text {dnonox }}\right.$ /glucose $\cdot \Delta$ insulin $)$ & $1.7 \pm 0.9$ & $2.6 \pm 1.9 * *$ & $0.5 \pm 0.4^{* \ddagger}$ & $1.1 \pm 0.6^{\ddagger \ddagger \ddagger}$ \\
\hline
\end{tabular}

Mean \pm SD, ANOVA; $* P<0.01$ vs control; ${ }^{8} P<0.02$ vs control; ${ }^{* *} P<0.05$ vs control; ${ }^{\ddagger} P<0.01$ vs IGF-I; $" P<0.02$ vs IGF-I; ${ }^{9} P<0.01$ vs $\mathrm{GH} ;{ }^{\ddagger} P<0.02$ vs $\mathrm{GH}$.

trol, 72.7 \pm 76.7 ; IGF-I, 192.1 $\pm 105.5 ; \mathrm{GH}, 207.3 \pm 272.4 ; \mathrm{GH}$ + IGF-I, 345.2 $\pm 160.7 \mu \mathrm{mol} /$ liter; Fig. 3).

Meal tolerance test (Fig. 1, Table V). Total and incremental areas under the curves (AUC and iAUC) of glucose were unchanged during IGF-I treatment as compared with control, albeit at a significantly reduced insulin secretion rate. During $\mathrm{GH}$ treatment, AUC and iAUC of glucose were significantly elevated. Additional IGF-I treatment again led to reduced insulin secretion, whereas glucose tolerance remained unchanged as compared with GH alone. IGF-I levels remained stable and unchanged as compared with basal values during the meal tolerance tests in the different treatment periods (not shown).

Indirect calorimetry (Fig. 2). Resting energy expenditure was $27.9 \pm 3.7 \mathrm{kcal} / \mathrm{kg}$ (FFM) - day during the control period, markedly elevated during IGF-I $(31.9 \pm 4.8)$ and GH (33.4 \pm 4.6$)$ treatment, and again more so during combination
$(35.0 \pm 2.8 \mathrm{kcal} / \mathrm{kg}[\mathrm{FFM}] \cdot$ day) therapy. Lipid oxidation was $11.6 \pm 3.5$ during control, elevated to $15.5 \pm 3.3$ during IGF-I and $17.2 \pm 4.1$ during $\mathrm{GH}$ treatment, and more so to $21.0 \pm 3.6 \mathrm{kcal} /$ $\mathrm{kg}$ (FFM) - day during combined treatment. Basal protein oxidation was $5.0 \pm 1.5$ during control, reduced by IGF-I to $3.8 \pm 1.1$ and by $\mathrm{GH}$ to $4.2 \pm 0.8$ and further reduced to $2.7 \pm 1.0 \mathrm{kcal} / \mathrm{kg}$ (FFM) - day when both hormones were given together. Carbohydrate oxidation was unchanged in all treatment phases, whereas nonoxidative glucose disposal in the basal state showed a tendency to be elevated during IGF-I and GH administration and was significantly $(P<0.05$ versus control $)$ elevated during the combination treatment (Table III).

Euglycemic, hyperinsulinemic clamp. Plasma glucose levels were similar in all four situations (Table VI). IGF-I levels during hyperinsulinemia were identical to the respective basal levels (Tables IV and VI). There were no significant rates of
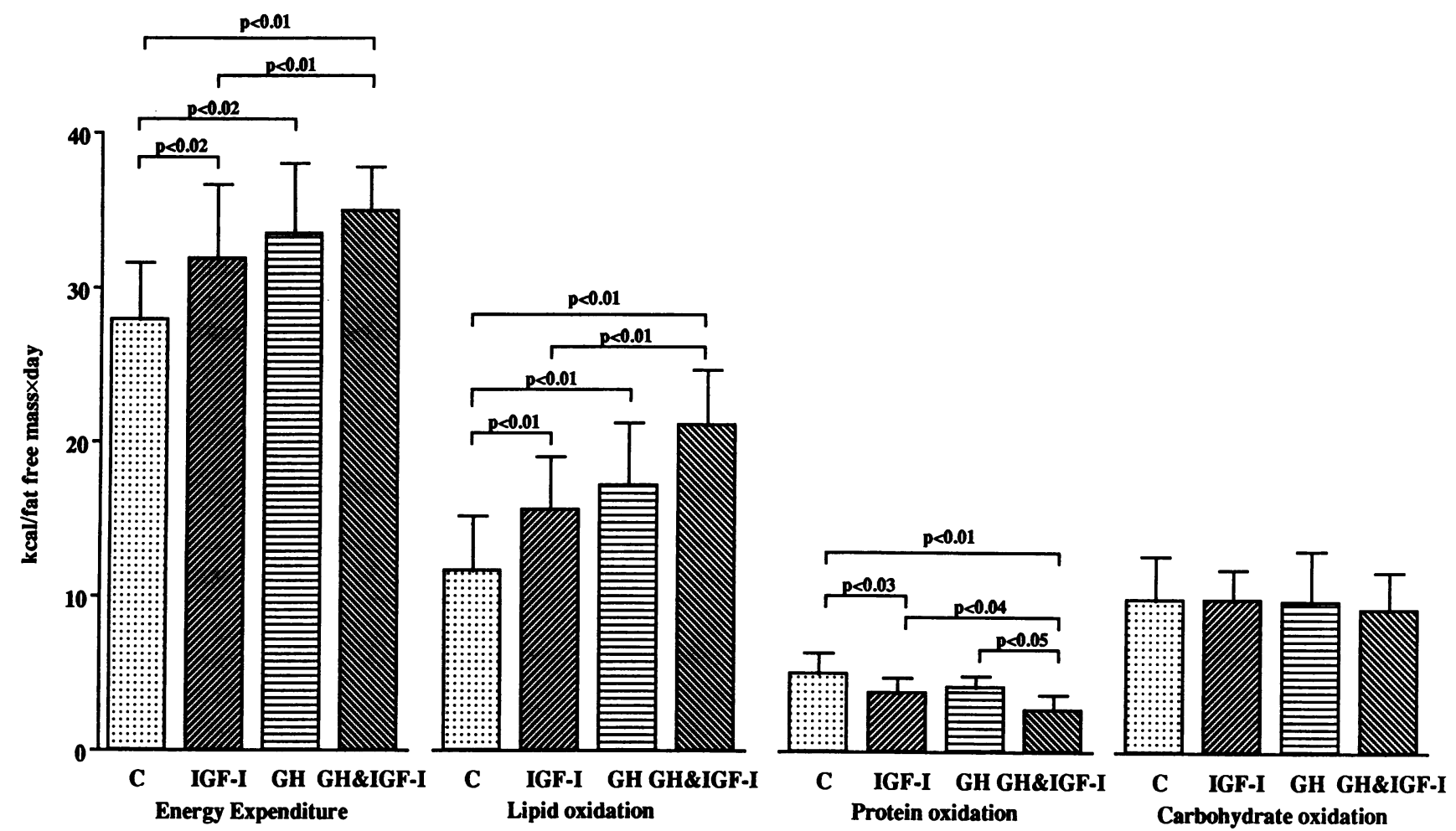

Figure 2. Basal energy expenditure and lipid, protein, and carbohydrate oxidation rates in eight GH-deficient subjects on day 7 of control (C), IGF-I, GH, and GH\&IGF-I treatment (mean \pm SD, ANOVA). 
Table III. Estimated Glucose Turnover Rates in the Basal State on Day 7 of Control, IGF-I, GH, and GH + IGF-I Treatment in Eight GH-deficient Subjects

\begin{tabular}{lcccc}
\hline & Control & IGF-I & GH & $\begin{array}{c}\text { GH }+ \\
\text { IGF-I }\end{array}$ \\
\hline $\mathrm{HGO}(\mathrm{mg} / \mathrm{kg}[F F M] \cdot \mathrm{min})$ & $2.0 \pm 0.3$ & $2.2 \pm 0.5$ & $2.3 \pm 0.3$ & $2.4 \pm 0.5^{*}$ \\
$R_{\mathrm{d}}(\mathrm{mg} / \mathrm{kg}[\mathrm{FFM}] \cdot \mathrm{min})$ & & & & \\
$\quad$ Oxidative & $1.7 \pm 0.5$ & $1.7 \pm 0.4$ & $1.7 \pm 0.6$ & $1.6 \pm 0.4$ \\
$\quad$ Nonoxidative & $0.3 \pm 0.4$ & $0.5 \pm 0.5$ & $0.7 \pm 0.6$ & $0.8 \pm 0.7^{*}$
\end{tabular}

Mean \pm SD, ANOVA; ${ }^{*} P<0.05$ vs control.

change for specific activity between the groups during insulin infusion (not shown). Insulin levels during the steady state period of the clamp were lower during the IGF-I treatment phase, elevated during GH treatment, and reduced again during the combination treatment period. C-peptide levels behaved similarly. Insulin-stimulated glucose uptake (insulin sensitivity index ) was elevated during IGF-I treatment, reduced during GH administration, and similar to control levels during the combination treatment (Table II). Calculated hepatic glucose output during clamping was less suppressed during GH and GH + IGFI treatment as compared with control and IGF-I alone. Insulin sensitivity indices of oxidative and nonoxidative glucose disposal rates $\left(\Delta R_{\mathrm{dox}} /\right.$ glucose $\cdot \Delta$ insulin and $\Delta R_{\text {dnonox }} /$ glucose $\cdot \Delta$ insulin; Table II) were elevated during IGF-I and reduced during GH treatment as compared with the control situation. IGFI treatment in addition to $\mathrm{GH}$ enhanced both oxidative and nonoxidative glucose disposal rates. Lipid oxidation rates during hyperinsulinemia were similar during control $(0.58 \pm 0.28)$ and IGF-I (0.66 \pm 0.23$)$, and elevated during GH $(0.92 \pm 0.21$, $P<0.05$ vs control and IGF-I) and combined GH + IGF-I $(1.17 \pm 0.20 \mathrm{mg} / \mathrm{kg}[\mathrm{FFM}] \cdot \mathrm{min}, P<0.05$ vs control and IGFI) therapy. Insulin infusion reduced FFA to lower levels during IGF-I as compared with control, whereas in the presence of GH, FFA levels were reduced less effectively during insulin administration irrespective of additional treatment with IGF-I (Table VI). During clamping, $\beta$-hydroxybutyric acid levels were not statistically different in the four treatment phases, although a tendency to higher levels was apparent during GH and during combination treatment (Table VI). FFM was unchanged during the treatment phases (not shown).
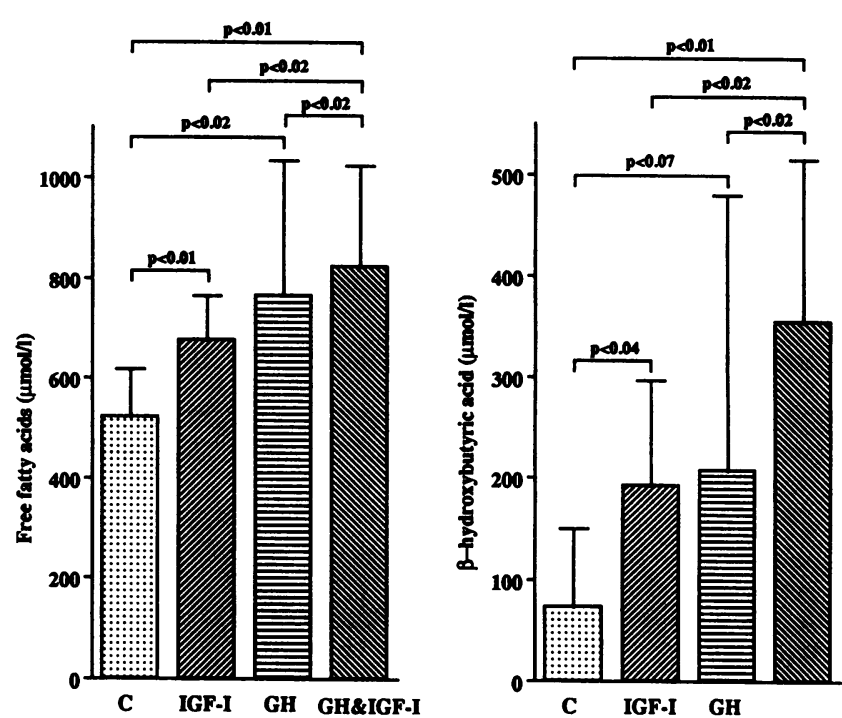

Figure 3. Free fatty acids and $\beta$-hydroxybutyric acid levels in fasting venous blood in eight GH-deficient subjects on day 7 of control $(C)$, IGF-I, GH, and GH\&IGF-I treatment (mean \pm SD, ANOVA).

\section{Discussion}

Effects of IGF-I in GH-deficient subjects in the presence and absence of $G H$. This study shows that even in the absence of GH, IGF-I increases energy expenditure, increases lipid oxidation, decreases protein oxidation, and increases insulin sensitivity. All these effects which have been observed during IGF-I treatment in normal humans $(11,14,15)$ are, therefore, independent of GH suppression. IGF-I primarily inhibits insulin secretion leading to increased lipolysis, lipid oxidation, and increased insulin sensitivity in skeletal muscle.

It is important to note that GH stimulates hepatic synthesis and secretion of IGF-I (1) and that our subjects had elevated IGF-I levels during GH treatment. In normal subjects, approximately $80 \%$ of the circulating IGF is found in a $150-\mathrm{kD}$ ternary complex consisting of an acid labile subunit, insulin-like growth factor binding protein 3, and IGF (22). IGF-I bound in this complex cannot cross vascular barriers and is therefore metabolically less active than free IGF $(23,24)$. The stabilization of this complex is largely dependent on the acid labile subunit, the synthesis of which is under strict control by GH (22).

Table IV. Serum Parameters in Fasting Venous Blood on Day 7 of Control, IGF-I, GH, and GH + IGF-I Treatment in Eight GH-deficient Subjects

\begin{tabular}{|c|c|c|c|c|}
\hline & Control & IGF-I & GH & GH + IGF-I \\
\hline Glucose (mmolliter) & $4.6 \pm 0.5$ & $4.3 \pm 0.3$ & $5.2 \pm 0.7^{* \pm}$ & $5.1 \pm 0.5^{* *}$ \\
\hline Total IGF-I (nmolliter) & $9.3 \pm 4.7$ & $54.8 \pm 18.9^{*}$ & $39.9 \pm 11.1^{* \neq}$ & $110.8 \pm 29.6^{8 \mid 11}$ \\
\hline Total IGF-II (nmolliter) & $52.5 \pm 19.2$ & $19.8 \pm 8.5^{* *}$ & $65.0 \pm 11.4^{811}$ & $36.2 \pm 12.0^{* * \neq \neq \pm}$ \\
\hline Growth hormone $(\mathrm{ng} / \mathrm{ml})$ & $0.38 \pm 0.42$ & $0.21 \pm 0.05$ & $3.27 \pm 1.44 * 11$ & $3.65 \pm 2.70 * \|$ \\
\hline Insulin (pmolniter) & $55.7 \pm 35.2$ & $40.8 \pm 13.1^{* *}$ & $140.8 \pm 105.2^{* \pm}$ & $65.5 \pm 29.1^{\ddagger \neq \ddagger}$ \\
\hline C-peptide (pmolliter) & $486.9 \pm 319.6$ & $183.8 \pm 150.7^{* *}$ & $992.2 \pm 597.4^{* * *}$ & $555.6 \pm 304.2^{\ddagger \neq \ddagger}$ \\
\hline
\end{tabular}

Mean \pm SD, ANOVA; ${ }^{*} P<0.01$ vs control; ${ }^{* *} P<0.02$ vs control; ${ }^{8} P<0.03$ vs control; " $P<0.01$ vs IGF-I; ${ }^{\ddagger} P<0.02$ vs IGF-I; ${ }^{9} P<0.01$ vs $\mathrm{GH} ;{ }^{\ddagger \ddagger} P<0.02$ vs $\mathrm{GH}$. 
Table V. AUC and iAUC of Glucose (in mmolliter $\cdot h$ ), Insulin, and $C$-peptide (in pmolliter $\cdot h$ ) during a Meal Tolerance Test in Six GH-deficient Subjects on Day 6 of Control, IGF-I, GH, and $G H+I G F-I$ Treatment in Six GH-deficient Subjects

\begin{tabular}{|c|c|c|c|}
\hline Treatment & $\mathrm{AUC}_{\text {gluosese }}$ & $\mathrm{AUC}_{\text {inemin }}$ & AUC $_{\text {c-peppide }}$ \\
\hline & $($ mmolhiter $\cdot h)$ & $(p m o l$ liter $\cdot h)$ & $(p m o h$ liter $\cdot h)$ \\
\hline Control & $5.0 \pm 0.6$ & $241.3 \pm 127.8$ & $1510.1 \pm 484.7$ \\
\hline IGF-I & $5.1 \pm 0.6$ & $128.8 \pm 49.5^{*}$ & $871.3 \pm 296.0 *$ \\
\hline GH & $6.4 \pm 0.9^{\ddagger 8}$ & $566.3 \pm 332.4^{\ddagger \S}$ & $2563.5 \pm 1128.2^{\ddagger 8}$ \\
\hline GH + IGF-I & $6.3 \pm 1.2^{\ddagger 8}$ & $387.2 \pm 178.7^{\neq \S \|}$ & $2135.0 \pm 549.2^{\ddagger \S} \|$ \\
\hline \multirow[t]{2}{*}{ Treatment } & iAUC $_{\text {gluosere }}$ & $\mathrm{iAUC}_{\text {insolin }}$ & ${ }_{i A U C}{ }_{C-\text { peppise }}$ \\
\hline & $($ mmolliter $\cdot h)$ & $(\mathrm{pmol} / \mathrm{liter} \cdot \mathrm{h})$ & $(p m o h$ liter $\cdot h)$ \\
\hline Control & $0.9 \pm 0.2$ & $194.0 \pm 121.2$ & $1037.6 \pm 361.6$ \\
\hline IGF-I & $1.0 \pm 0.4$ & $95.2 \pm 49.0^{*}$ & $590.0 \pm 347.6 *$ \\
\hline GH & $1.4 \pm 0.5^{\ddagger \S}$ & $461.4 \pm 251.4^{\ddagger 8}$ & $1620.2 \pm 530.1^{ \pm 8}$ \\
\hline GH + IGF-I & $1.5 \pm 0.9^{ \pm \S}$ & $276.8 \pm 168.3^{\ddagger \Sigma} \|$ & $1604.1 \pm 247.0^{\ddagger \S}$ \\
\hline
\end{tabular}

Mean \pm SD, ANOVA, ${ }^{\ddagger} P<0.02$ vs control; $* P<0.03$ vs control; ${ }^{8} P$ $<0.02$ vs IGF-I; " $P<0.03$ vs GH.

Thus, most of the endogenously synthesized IGF-I during GH treatment was sequestered in the $150-\mathrm{kD}$ complex and was metabolically less active than the exogenously administered IGF-I which was not bound in the complex and thus was readily available to tissues. Nevertheless, many changes observed during GH therapy are likely to have been mediated by endogenous IGF-I. Also, GH stimulates local IGF-I production in target tissues (25). Locally synthesized IGF-I may act in a paracrine fashion and contribute to some of the effects seen during GH treatment.

Energy expenditure and fuel oxidation (Fig. 2). Both IGFI and GH treatment led to similar effects on energy expenditure and substrate oxidation rates. Resting energy expenditure and lipid oxidation were increased, protein oxidation was decreased, and carbohydrate oxidation remained unchanged. The former three effects were additive when both hormones were given together. The elevated energy consumption serves several purposes: ( $a$ ) extra ATP production for anabolic processes; $(b)$ increased heat dissipation due to increased blood flow through the skin (Hussain, M., manuscript in preparation); and (c) possibly a somewhat increased futile glucose cycling, as has also been shown in acromegaly (see below and reference 26 ). The fuel for the extra energy was supplied by the oxidation of free fatty acids and ketone bodies. As shown in Fig. 3, free fatty acid and $\beta$-hydroxybutyric acid levels increased significantly, reflecting enhanced mobilization of caloric reserves from adipose tissue.

At this point it is important to note that adipocytes and hepatocytes, which are target tissues of $\mathrm{GH}$ and insulin, express few, if any, functional type I IGF receptors $(27,28)$. IGF-I can only act on these tissues at high concentrations by crossreacting with the insulin receptor. Since IGF-I binds to the insulin receptor with an affinity which is $1 / 100$ of that of insulin, a crossreaction of IGF-I with the insulin receptor is unlikely at the IGF-I levels reached during the present study (27). In contrast to adipocytes and hepatocytes, type I IGF receptors are abundant on skeletal muscle (29). Direct insulin-like effects of IGF-I (30) cannot be completely ruled out as an explanation for unchanged glucose disposal rate in the basal state in face of reduced insulin. Unchanged hepatic glucose output during IGF-I treatment, however, cannot be explained by insulin-like effects of IGF-I since, as noted above, hepatocytes do not express functional type I IGF receptors (28) and since, at the concentrations achieved, a crossreaction of IGF-I with the insulin receptor is unlikely (27). Insulin levels in the portal vein were apparently sufficient enough to keep hepatic glucose production from rising.

Mechanisms by which GH and IGF-I increase lipolysis. GH directly promotes lipolysis from adipose tissue by enhancing the reactivity of hormone-sensitive triglyceride lipase to lipolytic hormones (31). In addition, GH renders adipose tissue less sensitive to the antilipolytic effects of insulin. It has previously been shown by others $(6,32,33)$ and is supported by our findings (Table IV, Fig. 3) that, despite markedly increased insulin levels, FFA and $\beta$-hydroxybutyrate are increased by GH treatment. The mechanism behind increased FFA release from adipose tissue under IGF-I treatment is completely different. Since adipocytes lack functional type I IGF receptors (27), IGF-I cannot be the mediator of the lipolytic effects of GH. IGF-I presumably had an indirect lipolytic effect by inhibiting insulin secretion and, therefore, releasing the brakes on lipolysis. The additive effects of GH and IGF-I on lipolysis are, therefore, a combination of ( $a$ ) direct lipolytic effects of $\mathbf{G H}$ and $(b)$ inhibition by IGF-I of insulin secretion, i.e., decreased levels of the major antilipolytic hormone $(10,13,34)$. Insulin infusion reduced FFA, i.e., lipolysis, during IGF-I treatment to lower levels than in the control situation. This cannot be explained by insulin-like effects of IGF-I since IGF-I (at the same

Table VI. Serum Parameters during Euglycemic, Hyperinsulinemic Clamp on Day 7 of Control, IGF-I, GH, and GH + IGF-I Treatment in Eight GH-deficient Subjects

\begin{tabular}{|c|c|c|c|c|}
\hline & Control & IGF-I & GH & GH + IGF-I \\
\hline Glucose (mmolliter) & $5.0 \pm 0.2$ & $5.0 \pm 0.3$ & $5.0 \pm 0.1$ & $5.0 \pm 0.2$ \\
\hline Total IGF-I (nmolliter) & $9.3 \pm 5.0$ & $54.6 \pm 18.5^{*}$ & $40.1 \pm 7.3^{* \ddagger}$ & $109.8 \pm 28.9 * 81$ \\
\hline Insulin (pmoLliter) & $335 \pm 79$ & $244 \pm 41 *$ & $343 \pm 85^{\| \ddagger}$ & $256 \pm 40^{* \pm * *}$ \\
\hline C-peptide (pmolliter) & $470 \pm 345$ & $229 \pm 162 *$ & $581 \pm 496^{* \ddagger}$ & $344 \pm 208^{* * * *}$ \\
\hline FFA ( $\mu$ mol/liter) & $49 \pm 38$ & $36 \pm 36^{\prime \prime}$ & $107 \pm 72^{* 8}$ & $175 \pm 11^{* 8}$ \\
\hline$\beta$-Hydroxybutyric acid ( $\mu$ molliter) & $6.9 \pm 4.6$ & $5.2 \pm 1.0$ & $9.4 \pm 15.0$ & $11.0 \pm 12.9$ \\
\hline
\end{tabular}

Mean \pm SD, ANOVA; ${ }^{*} P<0.01$ vs control; " $P<0.02$ vs control; ${ }^{\ddagger} P<0.01$ vs IGF-I; ${ }^{8} P<0.02$ vs IGF-I; ${ }^{* *} P<0.01$ vs GH; ${ }^{9} P<0.02$ vs $\mathrm{GH}$. 
level as during hyperinsulinemic clamping) would then, in contrast to our findings, suppress basal FFA levels. Furthermore, a recent publication has shown that even acute infusions of IGFI at doses which lead to changes in serum amino acid and glucose levels are not accompanied by antilipolytic effects (35). Insulin sensitivity of adipose and other tissues can be increased by several mechanisms. Reduced basal glucose as well as reduced insulin levels may enhance insulin sensitivity $(36,37)$. It is therefore likely that these indirect effects of IGF-I have led to enhanced insulin sensitivity of adipose tissue.

During GH treatment, a comparable suppression of lipolysis was not achieved. These findings support the concept that GH directly promotes lipolytic activity which cannot be fully counteracted by insulin. In contrast, the lipolytic effect of IGF-I is a result of reduced basal insulin levels which can be readily reversed by exogenous insulin.

Effects of GH and IGF-I on insulin secretion and basal and insulin-stimulated glucose metabolism. Basal insulin levels were decreased during IGF-I treatment, elevated during GH treatment, and were again reduced when IGF-I was given in addition to GH. These effects of GH and IGF-I are in line with those of previous reports $(7-11,13)$. During clamping, insulin was infused at identical rates in all four situations. However, steady state levels of insulin during insulin infusion were lower during IGF-I treatment, elevated during GH period, and reduced again when IGF-I was added to GH treatment. These changes are readily explained by direct inhibitory effects of IGF-I on insulin secretion (13), as is also reflected by the reduced Cpeptide levels during clamping (Table VI). Reduced insulin levels could also be explained by a shortened half-life due to IGF-I treatment. However, in a study addressing this question we have found no change in insulin half-life during IGF-I treatment (Hussain, M.A., manuscript in preparation). Most of the basal glucose combustion takes place in insulin-independent tissues $(38,39)$. During insulin stimulation, i.e., postprandially or during hyperinsulinemic clamping, glucose is taken up by insulin-dependent tissues of which skeletal muscle constitutes the largest part (39). Skeletal muscle is also the main tissue carrying both insulin and type I IGF receptors, whereas other target tissues of insulin carry few IGF receptors. Should IGF-I directly induce increased insulin sensitivity, probably by specific receptor-mediated action, this would only be demonstrable (a) in tissues carrying both type I IGF receptors as well as insulin receptors for which skeletal muscle is the example of choice and $(b)$ during insulin stimulation.

Fasting glucose levels were slightly but not significantly decreased by IGF-I and significantly increased by GH. These glycemic changes were small compared with the large differences of fasting insulin levels. Also, addition of IGF-I during GH treatment did not significantly alter the basal glucose levels as compared with GH treatment alone. These results are in line with previous observations that GH plays a key role in the complex regulation of basal glucose levels $(38,39)$. The elevated hepatic glucose output and nonoxidative glucose disposal rates under the combined treatment may be due to an increased futile cycling of glucose in the liver reflecting a combination of insulin resistance induced by $\mathrm{GH}$ on one hand and reduced insulin availability due to inhibition of insulin secretion by IGFI on the other hand. In acromegalics, who also have elevated GH and IGF-I levels, increased glucose cycling has also been described (26). Insulin-like effects of IGF-I can be excluded as a mechanism behind the increased basal glucose turnover, since glucose oxidation rates were unaltered in all treatment phases despite elevated resting energy expenditure.

Insulin sensitivity was determined by the sensitivity index (20) to account for possible insulin-like effects of IGF-I (30) and since basal and steady state insulin levels during clamping varied during the different treatment periods (Tables IV and VI). Insulin sensitivity of peripheral tissues was increased by IGF-I treatment alone and was reduced during GH treatment. Addition of IGF-I on top of GH treatment reversed the GH effect on insulin sensitivity on peripheral tissues. In a previous study, we demonstrated that IGF-I treatment enhances insulin sensitivity in healthy subjects (6). However, it remained unclear whether IGF-I enhanced insulin sensitivity directly or indirectly through feedback inhibition of GH secretion. In the present study, IGF-I administration reversed the insulin resistance induced by GH treatment, suggesting that IGF-I directly enhances insulin sensitivity irrespective of the GH status. Independent of concomitant GH treatment, IGF-I treatment was accompanied by increased oxidative as well as nonoxidative glucose disposal relative to the actual insulin level. As noted above, the major site of enhanced insulin sensitivity under these conditions most likely is skeletal muscle. The results of the meal tolerance tests corroborate the findings of the euglycemic clamps.

Hepatic glucose output (HGO) was suppressed completely during the steady state period of the hyperinsulinemic clamp during the control as well as during the IGF-I treatment period. During GH treatment, a complete suppression of HGO was, as would be expected (9), not achieved. IGF-I treatment in addition to GH had no influence on steady state HGO during hyperinsulinemia. Nevertheless, IGF-I treatment may have altered the kinetics in change of HGO during clamping. The data of the present study, however, do not allow interpretation of changes in HGO during the course of insulin infusion. Moreover, since portal insulin levels are not known, reliable information on hepatic insulin sensitivity cannot be derived.

Effects of GH and IGF-I on protein oxidation. Reduction of protein oxidation, i.e., of proteolysis, was observed under IGF-I as well as GH treatment. When both hormones were given together, the effects of IGF-I and GH were additive. These findings support those of a previous report also showing that anabolism may be stimulated to a greater extent by treatment with GH and IGF-I together than by either hormone alone (40). Moreover, insulin-like properties of IGF-I (30) and the fact that IGF-I increases insulin sensitivity of skeletal muscle may allow us to preserve normal glucose tolerance when GH and IGF-I stimulate protein anabolism in a concerted fashion.

In conclusion, our results show that IGF-I per se is a potent anticatabolic agent (as in regard to protein metabolism) leading by way of partial inhibition of insulin secretion to increased lipolysis and fat oxidation. These effects of IGF-I are independent of the inhibitory effect on growth hormone secretion. All these effects of IGF-I are, however, synergistic to those of GH, which stimulates lipolysis and possibly protein anabolism through mechanisms different from those of IGF-I. In the case of simultaneous administration of GH and IGF-I, insulin levels lie between those attained by IGF-I treatment alone and those observed during GH treatment. Since insulin is an important anabolic hormone (41), it is conceivable that in situations of severe catabolism a combination of GH and IGF-I together will turn out to give the best results with regard to anticatabolism and anabolism (40). 


\section{Acknowledgments}

We thank A. Keller and Dr. S. E. Jäggi-Groisman for their superb technical assistance and Dr. C. Schmid for critical review of the manuscript. We also thank Dr. K. G. M. M. Alberti for analyzing $\beta-O H$ butyric acid and Dr. M. Ader for the advice in calculating the insulin sensitivity index.

This work was supported by the Swiss National Science Foundation grant 32-31281.91.

\section{References}

1. Schwander, J. C., C. Hauri, J. Zapf, and E. R. Froesch. 1983. Synthesis and secretion of insulin-like growth factor and its binding protein by the perfused rat liver: dependence on growth hormone status. Endocrinology. 113:297-305.

2. Salmon, W. D., Jr., and W. H. Daughaday. 1957. A hormonally controlled serum factor which stimulates sulfate incorporation by cartilage in vivo. J. Lab. Clin. Med. 49:825-836.

3. Van-Buul-Offers, S., I. Ueda, and J. L. Van den Brande. 1986. Biosynthetic somatomedin C (SM-C/IGF-I) increases the length and weight of Snell dwarf mice. Pediatr. Res. 20:825-827.

4. Schoenle, E., J. Zapf, R. E. Humbel, and E. R. Froesch. 1982. Insulin-like growth factor I stimulates growth in hypophysectomized rats. Nature (Lond.). 323:169-171.

5. Laron, Z., S. Anin, Y. Klipper-Aurbach, and B. Klinger. 1992. Effects of insulin-like growth factor on linear growth, head circumference, and body fat in patients with Laron-type dwarfism. Lancet. 339:1258-1261.

6. Hussain, M. A., O. Schmitz, A. Mengel, A. Keller, J. S. Christiansen, J. Zapf, and E. R. Froesch. 1993. Insulin-like growth factor I stimulates lipid oxidation, reduces protein oxidation, and enhances insulin sensitivity in humans. $J$. Clin. Invest. 92:2249-2256.

7. Barutsch-Marrain, P. R., D. Smith, and R. A. DeFronzo. 1982. The effect of growth hormone on glucose metabolism and insulin secretion in man. J. Clin. Endocrinol. \& Metab. 55:973-982.

8. Salomon, F., R. C. Cuneo, R. Hesp, and P. Sonksen. 1989. The effects of treatment with recombinant human growth hormone on body composition and metabolism in adults with growth hormone deficiency. N. Engl. J. Med. 321:17971803.

9. Rizza, R., L. W. Mandarino, and J. E. Gerich. 1982. Effects of growth hormone on insulin action in man. Mechanisms of insulin resistance, impaired suppression of glucose production, and impaired stimulation of glucose utilization. Diabetes. 31:663-669.

10. Sherwin, R. S., R. G. Hendler, and P. Felig. 1983. Effect of growth hormone on oral glucose tolerance and circulating metabolic fuels in man. Diabe tologia. 24:155-161.

11. Guler, H. P., C. Schmid, J. Zapf, and E. R. Froesch. 1989. Effects of recombinant insulin-like growth factor on insulin secretion and renal function in normal human subjects. Proc. Natl. Acad. Sci. USA. 86:2868-2872.

12. Berelowitz, M., M. Szabo, L. A. Frohman, S. Firestone, and L. Chu. 1981 Somatomedin-C mediates growth hormone negative feedback by effects on both hypothalamus and the pituitary. Science (Wash. DC). 212:1279-1281.

13. Leahy, J. L., and K. M. Vandekerkhove. 1990. Insulin-like growth factor at physiological concentrations is a potent inhibitor of insulin secretion. Endocrinology. 126:1593-1598.

14. Zenobi, P. D., S. Graf, H. Ursprung, and E. R. Froesch. 1992. Effects of insulin-like growth factor-I on glucose tolerance, insulin levels, and insulin secretion. J. Clin. Invest. 89:1908-1913.

15. DeFronzo, R. A., D. Tobin, and R. Anders. 1979. Glucose clamp technique: a method for quantifying insulin secretion and insulin resistance. Am. J. Physiol. 273:E214-E223.

16. Molina, M. J., A. D. Baron, S. V. Edelmann, G. Brechtel, P. Wallace, and J. M. Olefsky. 1990. Use of a variable tracer infusion method to determine glucose turnover in humans. Am. J. Physiol. 258:E216-E232.

17. Segal, K. R., M. Van Loan, P. I. Fitzgerald, J. A. Hodgson, and T. B. Van Italie. 1988. Lean body mass estimation by bioelectrical impedance analysis: a four-site cross validation study. Am. J. Clin. Nutr. 47:7-14.

18. Elia, M., and G. Livesey. 1988. Theory and validity of indirect calorimetry during net lipid synthesis. Am. J. Clin. Nutr. 47:591-607.

19. deBodo, R., R. Steele, N. Altszuler, A. Dunn, and J. Bishop. 1963. On the hormonal regulation of carbohydrate metabolism: studies with ${ }^{14} \mathrm{C}$ glucose. Recent Prog. Horm. Res. 19:445-488.

20. Bergman, R. N., I. D. Hope, Y. J. Yang, R. N. Watanabe, M. A. Meador, J. H. Youn, and M. Ader. 1989. Assessment of insulin sensitivity in vivo. A critical review. Diabetes Metab. Rev. 5:411-429.

21. Ciba-Geigy Limited. 1982. Geigy Scientific Charts, Volume 2, 8th Edition. Ciba-Geigy Ltd., Basel. 209-210.

22. Baxter, R. C., and J. L. Martin. 1989. Structure of the $M_{\mathrm{r}} 140,000$ growth hormone-dependent insulin-like growth factor binding protein complex: determination by reconstitution and affinity-labeling. Proc. Natl. Acad. Sci. USA. 86:6898-6902.

23. Binoux, M., and P. Hossenlopp. 1988. Insulin-like growth factor (IGF) and IGF-binding proteins: comparison of human serum and lymph. J. Clin. Endocrinol. \& Metab. 67:509-514.

24. Bar, R. S., D. R. Clemmons, M. Boes, W. H. Busby, B. A. Booth, B. L. Dake, and A. Sandra. 1990. Transcapillary permeability and subendothelial distribution of endothelial and amniotic fluid insulin-like growth factor binding proteins in the rat heart. Endocrinology. 127:1078-1086.

25. D'Ercole, A. J., A. D. Stiles, and L. E. Underwood. 1984. Tissue concentrations of somatomedin C: further evidence for multiple sites of synthesis and paracrine or autocrine mechanisms of action. Proc. Natl. Acad. Sci. USA. 81:935939.

26. Karlander, S., M. Vranic, and S. Efendic. 1986. Increased glucose turnover and glucose cycling in acromegalic patients with normal glucose tolerance. Diabetologia. 29:778-783.

27. Caro, J. F., J. Poulos, O. Ittoop, W. J. Pories, E. G. Flickinger, and M. K. Sinha. 1988. Insulin-like growth factor I binding in hepatocytes from human liver, human hepatoma, and normal, regenerating, and fetal rat liver. J. Clin. Invest. 81:976-981.

28. Zapf, J., E. Schoenle, M. Waldvogel, I. Sand, and E. R. Froesch. 1981. Effect of trypsin treatment of rat adipocytes on biological effects and binding of insulin and insulin-like growth factors. Further evidence for the action of insulinlike growth factors through the insulin receptor. Eur. J. Biochem. 113:605-609.

29. Poggi, C., Y. Le Marchand-Brustel, J. Zapf, E. R. Froesch, and P. Freychet. 1979. Effects and binding of insulin-like growth factor in the isolated soleus muscle of lean and obese mice. Endocrinology. 195:732-730.

30. Guler, H. P., J. Zapf, and E. R. Froesch. 1987. Short-term metabolic effects of recombinant human insulin-like growth factor $I$ in healthy adults. $N$. Engl. J. Med. 217:137-140.

31. Dietz, J., and J. Schwartz. 1991. Growth hormone alters lipolysis and hormone-sensitive lipase activity in 3T3-F442A adipocytes. Metab. Clin. Exp. 40:800-806.

32. Moller, N., J. O. L. Jorgensen, O. Schmitz, J. Moller, J. S. Christiansen, K. G. M. M. Alberti, and H. Orskov. 1990. Effects of a growth hormone pulse on total and forearm substrate fluxes in humans. Am. J. Physiol. E86-E91.

33. Bak, J. F., N. Moller, and O. Schmitz. 1991. Effects of growth hormone on fuel utilization and muscle glycogen synthase activity in normal humans. Am. J. Physiol. 260:E736-E742.

34. Jensen, M. D., M. Caruso, V. J. Heiling, and J. M. Miles. 1989. Insulin regulation of lipolysis in nondiabetic and IDDM subjects. Diabetes. 38:13951401.

35. Elahi, D., M. McAloon-Dyke, N. K. Fukagawa, A. L. Sclater, G. A. Wong, R. P. Shannon, K. L. Minaker, J. M. Miles, A. H. Rubenstein, C. J. Vanderpol, et al. 1993. Effects of recombinant human IGF-I on glucose and leucine kinetics in men. Am. J. Physiol. 265:E831-E838.

36. Bar, R. S., L. C. Harrison, M. Muggeo, P. Gorden, C. R. Kahn, and J. Roth. 1979. Regulation of insulin receptors in normal and abnormal physiology in humans. Adv. Intern. Med. 24:23-52.

37. Rossetti, L., D. Smith, G. I. Shulman, D. Papachristou, and R. A. DeFronzo. 1987. Correction of hyperglycemia with phlorizin normalizes tissue sensitivity to insulin in diabetic rats. J. Clin. Invest. 79:1510-1515.

38. DeFronzo, R. A., and E. Ferranini. 1987. Regulation of hepatic glucose metabolism in humans. Diabetes Metab. Rev. 3:415-459.

39. DeFronzo, R. A., E. Jacot, E. Jequier, E. Maeder, J. Wahren, and J. P. Felber. 1981. The effect of insulin on the disposal of intravenous glucose. Results from indirect calorimetry and femoral venous catheterization. Diabetes. 30:10001007.

40. Kupfer, S. R., L. E. Underwood, R. C. Baxter, and D. R. Clemmons. 1993. Enhancement of the anabolic effects of growth hormone and insulin-like growth factor I by the use of both agents simultaneously. J. Clin. Invest. 91:391396.

41. Fukagawa, N. K., K. L. Minaker, J. W. Rowe, M. N. Goodman, D. E. Mattews, D. M. Bier, and V. R. Young. 1985. Insulin-mediated reduction of whole body protein breakdown. Dose-response effects on leucine metabolism in postabsorptive men. J. Clin. Invest. 76:2306-2311. 